\title{
Porträts, Blumen und Passion
}

Felix Schürch

Korrespondenz:

Dr. med. Felix Schürch

Albulastrasse 52

CH-8048 Zürich

felix.schurch[at]hin.ch

www.hausarztfelixschürch.ch

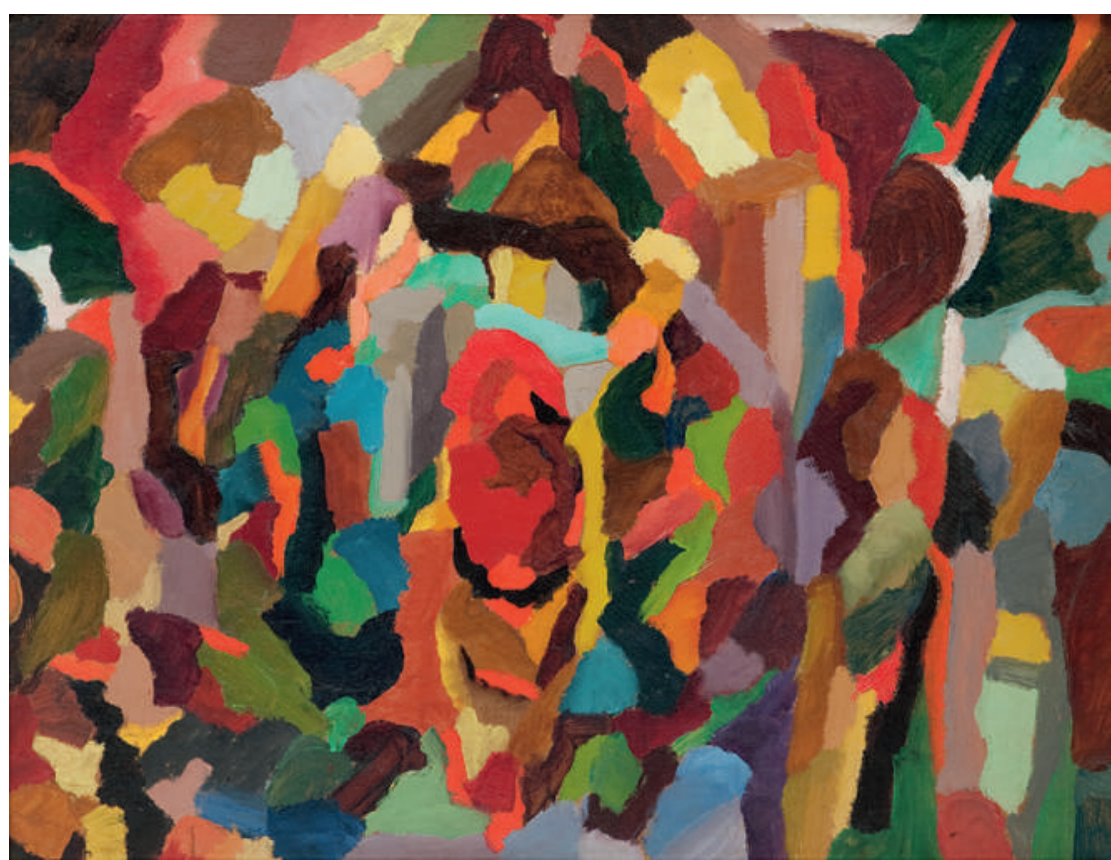

Anna Iduna Zehnder, Passionsgeschichte, 1. Station, Jesus wird zum Tode verurteilt, 1923.

Beim Eingang zur Ausstellung im Aargauer Kunsthaus blickt sie uns entgegen: Anna Iduna Zehnder. Ihr Blick ist aufmerksam, ruhig und konzentriert. Als vierzigjährige Frau malte die Künstlerin dieses Selbstporträt. Das Bild hat die Grösse von zwei A4-Blättern und besteht aus unzähligen farbigen Pixeln. Zehnder hatte sich die Technik des Pointillismus in der Malschule von Arthur Segal in Ascona angeeignet. Das Selbstporträt aus dem Jahr 1917 und ein paar weitere Bilder zeigen eine ausserordentliche Frau bei ihren ersten Gehversuchen als Malerin.

Später wird Anna Iduna Zehnder die Farbe flächiger auftragen und kräftige Landschaften, expressive Porträts und pralle Blumenstillleben malen. Es kommen abstrakte Kompositionen hinzu, bei denen höchstens noch andeutungsweise Gegenstände und Figuren erkennbar sind. Rein kunstgeschichtlich ist diese Malerin kaum einzuordnen. Mit Impressionismus und Expressionismus, Orphismus und Symbolismus lassen sich vielleicht einzelne Bilder etikettieren - für das in Aarau präsentierte Gesamtwerk passt keine Kategorie für sich allein. Was soll's! Wir lassen uns überwältigen von der reichen Farbpalette und den überraschenden Kontrasten. Die Bilder wirken so frisch, als kämen sie direkt aus dem Atelier und als wären ihre Oberflächen noch feucht. Das Aargauer Kunsthaus hat der Werkschau im Untergeschoss viel

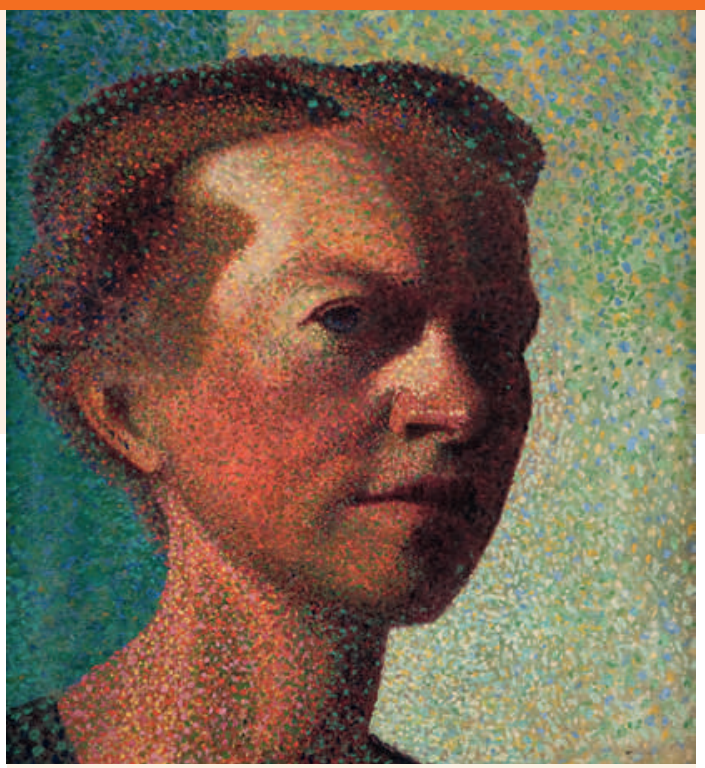

Anna Iduna Zehnder, Selbstporträt, 1917.

Platz eingeräumt, die relativ kleinen Bilder dürfen ihre Wirkung an den grossen Wänden entfalten.

Die Künstlerin Anna Iduna Zehnder (1877-1955) war eine ausserordentliche Frau. Sie setzte sich mit der avantgardistischen Kunst ihrer Zeit auseinander, mit Matisse, Jawlensky, Klee. Sie vertiefte sich in die Anthroposophie und stand in persönlichem Kontakt mit Rudolf Steiner. Sie kannte die Utopisten und Visionäre vom Monte Verità in Ascona. 1904 begann sie das Medizinstudium in Basel, und 1914 bekam sie als eine von wenigen Frauen das staatliche Arztpatent. Die Medizin war die «erste» Berufung der Künstlerin und zugleich war sie ihr Brotberuf. Zunächst machte sie Praxisvertretungen, dann übernahm sie die Dorfpraxis in ihrem Wohnort Ascona. Anna Iduna Zehnder war immer wieder mit Krankheit und Leiden konfrontiert - nicht nur im Beruf, auch persönlich: Als Anna fünf Jahre alt war, starben ihre Eltern. Das Studium musste sie wegen Tuberkulose mehrmals unterbrechen. Ihre langjährige Lebenspartnerin Emmy Turnherr litt an einer schweren Augenkrankheit. Mit knapp fünfzig Jahren kämpfte die Ärztin und Künstlerin, erschöpft und überarbeitet, gegen einen Zustand, den man heute wohl als Burn-out bezeichnen würde.

Einer der Ausstellungsräume versammelt einen Zyklus mit Bildern aus dem Jahre 1923, in denen die Passionsgeschichte thematisiert wird. Die biblischen Episoden bleiben weitgehend verborgen in diesen teppichartigen Farbkompositionen. Mit etwas Phantasie kann der Betrachter einzelne Figuren und Szenen in die Bilder hineinprojizieren. Einfacher ist es, die Bilder als Musik aufzufassen. Als Kammermusik mit hellen und dunklen Klängen, harten und weichen Rhythmen. Den Anfang des Zyklus macht das Bild «Jesus wird zum Tode verurteilt» - eine aufwühlende Szene. Es ist ein Bild mit blutroten Flecken und grünen Einschüben, mit Lichtstrahlen und dunklen Brauntönen. Das «Todesurteil» einer schwerwiegenden Diagnose löst Krisen aus. Das wusste die Ärztin Anna Iduna Zehnder. Die Künstlerin Anna Iduna Zehnder versuchte es malend zu fassen und zu ordnen: das Chaos von Leben und Tod. 